Portland State University

PDXScholar

Civil and Environmental Engineering Faculty

Publications and Presentations

2017

\title{
Impact of Last Mile Parking Availability on Commercial Vehicle Costs and Operations
}

\author{
Miguel Figliozzi \\ Portland State University, figliozzi@pdx.edu \\ Chawalit Tipagornwong \\ Portland State University
}

Follow this and additional works at: https://pdxscholar.library.pdx.edu/cengin_fac

Part of the Transportation Commons, and the Urban Studies Commons Let us know how access to this document benefits you.

\section{Citation Details}

Published as: Figliozzi, M., \& Tipagornwong, C. (2017, April). Impact of last mile parking availability on commercial vehicle costs and operations. In Supply Chain Forum: An International Journal (Vol. 18, No. 2, pp. 60-68). Taylor \& Francis.

This Pre-Print is brought to you for free and open access. It has been accepted for inclusion in Civil and Environmental Engineering Faculty Publications and Presentations by an authorized administrator of PDXScholar. Please contact us if we can make this document more accessible: pdxscholar@pdx.edu. 


\title{
Impact of Last Mile Parking Availability on Commercial Vehicle Costs and Operations
}

\author{
Miguel Figliozzi $^{1}$ and Chawalit Tipagornwong ${ }^{1}$ \\ ${ }^{1}$ Department of Civil and Environmental Engineering, Portland State University. P.O. Box 751, \\ Portland, Oregon 97207-0751, USA.figliozzi@pdx.edu
}

\begin{abstract}
:
This research analyses how parking availability levels affect commercial vehicle parking costs and operations in congested urban areas. Unlike passenger vehicles, parking availability has an impact on route characteristics and commercial vehicle fleet sizes. Hence, commercial vehicles parking costs cannot be captured solely by estimating delays and/or the cost of parking fines. This research combines logistics, queuing, and optimization models to study the impact of last mile parking availability on commercial vehicle costs and operations. Scenarios are built to study the impact of parking availability on typical less-than-truckload (LTL) and courier service costs. Results indicate that parking availability levels do affect commercial vehicle costs and operations significantly. The magnitude of the impacts is a function of customer and route characteristics. The analysis of elasticity values indicates that a few variables have a significant impact on commercial vehicle parking behaviour. In some cases, productivity improvements like service time reductions may result in undesirable changes in commercial vehicle parking behaviour.
\end{abstract}

Keywords: commercial vehicles; last mile; parking costs; economic analysis; elasticity

\section{Journal Reference}

Figliozzi, M. A. \& Tipagornwong, C. (2017). Impact of Last Mile Parking Availability on Commercial Vehicle Costs and Operations. Supply Chain Forum: an International Journal, 18:2, 60-68. 


\section{Introduction}

There is a growing awareness regarding problems associated with commercial vehicles in congested urban areas. Efforts to increase downtown or neighbourhood livability can result in costly restrictions. Typical restrictions include commercial vehicle bans at certain times of the day, limited parking and/or loading and/or unloading zones for commercial vehicles, commercial vehicle noise level limits (when loading and unloading), commercial vehicles pollution constraints, and commercial vehicles size limits. For example, in New York City commercial vehicle size, routes, and parking areas are restricted for urban freight distributors and service providers (City of New York, 2013).

On-street parking spaces and freight loading zones (FLZs) are typically insufficient during certain periods of the day in most dense and congested urban areas, for example in the USA these urban areas include New York City, San Francisco, Los Angeles, Boston, Chicago, and Washington D.C. News organizations frequently report on the problems caused by double-parked commercial vehicles or the high parking fines that delivery companies must pay (NBC News, 2006; Gordon, 2007; Halsey, 2013; Hawkins, 2013; Berezin, 2014).

Although anyone that lives in a dense and congested city is familiar with the problems associated to commercial vehicle parking there is limited research in this area. In particular, there is scant research related to models that attempt to understand the impacts of FLZ availability on commercial vehicles costs and behaviour. This study addresses the following research questions: how does parking availability affect distribution companies' parking behaviour? and (ii) what are the key variables that affect parking costs?

Next section discusses key aspects of the problem under study and presents a brief literature review. Later sections present a modelling framework that includes queueing, 
logistics, and cost optimization models. A case study that includes different delivery services types is analysed and cost elasticity and break-even values are discussed. The final sections discuss policy and managerial implications and summarize the main conclusions that can be derived from this research effort.

\section{Background and Brief Literature Review}

When all parking spaces near delivery destinations are occupied, commercial drivers prefer not to park away from the delivery destination (Pluvinet et al., 2012). Several factors explain this preference. It is difficult to move bulky or heavy products over long distances or across intersections even if the driver or delivery person is utilizing a hand truck (Allen et al. 2000). In some cities or neighbourhoods, drivers may prefer to see their vehicles to prevent theft and/or vandalism (Morris, Kornhauser and Kay, 1999). In addition, parking away from the delivery points adds time per delivery and small delays quickly become significant for drivers or companies that have to serve many customers along the route (Figliozzi, 2007, Figliozzi \& Tipagornwong, 2016).

When there is no parking available nearby the delivery point commercial drivers may double park. If commercial drivers double park frequently, the cost of parking fines can be substantial. For example in New York City, large delivery fleets including FedEx, UPS, and the U.S. Postal Service paid \$550 million in 2013 (Hawkins, 2013). Since repeated double parking fines increase the final delivery cost, urban freight distributors and service providers may raise service fees to customers in areas where deliveries or pick-ups are more difficult. For example, UPS charges a surcharge in some congested or difficult delivery areas (such as zip codes 10000 - 10292) of Manhattan, New York City (United Parcel Service of America, 2015).

Previous research efforts have modelled parking availability by analysing a parking demand-to-supply ratio that is defined as the ratio between parking demand and 
parking supply rates. Some publications define the parking demand rate as a freight trip generation rate multiplied by the average parking time; for example, Jaller et al. (2013) studied off-peak-hour deliveries and evaluated commercial parking availability with the parking demand-to-supply ratio at different times of day in New York City. The freight trip generation rate has been traditionally estimated as a function of the number of employees by type of industry, commercial sector, or land use (Fischer and Han, 2001). The parking supply is defined as the number of parking spaces or FLZs. The literature based on the analysis of empirical demand/supply data largely agree that at peak times there is insufficient parking capacity in commercial districts and along urban arterials (Wenneman, Habib, and Roorda, 2015) and even in neighbourhoods (Chen and Conway, 2016).

Another line of research has utilized simulation models (for example, Aiura and Taniguchi, 2006 and McLeod and Cherrett, 2011) to study commercial vehicle parking in urban areas. These models can accurately represent transportation networks and FLZs, generate commercial vehicle trips and their parking time, and estimate commercial vehicles delays. A recent model to analyse parking policies in specific locations combines parking choice models and a traffic simulation models (Nourinejad, et al., 2014).

The third approach is a statistical model. For example, a statistical model (based on queuing theory) has been used to study how personal or passenger parking demand responds to pricing and parking availability in San Francisco (Millard-Ball, Weinberger, \& Hampshire, 2014). This type of modeling effort can be used to investigate the impact of pricing on parking arrival rate, parking duration, and parking availability. Unfortunately, there is no similar dataset that can be utilized to study the impacts of pricing and parking availability on commercial vehicles. A previous paper by the same 
authors was preliminary (conference proceedings) and did not include a discussion of elasticity values and policy/managerial implications (Figliozzi \& Tipagornwong, 2016).

Unlike previous research efforts, this research focuses on modelling parking availability combining queuing models and logistical models based on continuous approximations. Unique contributions of this research are the addition of real-world routing constraints such as load capacity or route time durations, the analysis and comparison of courier and less-than-truckload (LTL), and ranking the impact of logistics and policy variables as a function of their elasticity values. Next section presents the modelling framework integrating queuing and continuous approximations for long-term logistic costs.

\section{Modelling Commercial Parking}

This research models parking availability utilizing queuing models. Routing constraints are modelled utilizing continuous approximations. Service costs includes all the relevant long-term (vehicle and driver) costs. Finally, all the models are integrated within an optimization framework that can be utilized to determine the optimal number of vehicles, vehicle type, and parking behaviour.

\section{Parking availability}

Convenient access is important for both consumers and carriers (Duran \& GonzalesFeliu, 2012) hence the number of available parking spots is usually limited. Assuming that there are (S) freight loading zones available on a first-come-first-serve basis and that inter-arrival times and FLZ occupation times follow exponential distributions, a $\mathrm{M} / \mathrm{M} / \mathrm{S}$ queuing model can be utilized. The expected probability of double parking $(\mathrm{P}(\mathrm{N} \geq \mathrm{S}))$ can be estimated as follows: 


$$
\begin{gathered}
\mathrm{P}(\mathrm{N} \geq \mathrm{S})=1-\mathrm{P}(\mathrm{N} \leq \mathrm{S}-1)=1-\sum_{\mathrm{N}=0}^{\mathrm{S}-1} \frac{(\lambda / \mu)^{\mathrm{N}}}{\mathrm{N} !} \mathrm{P}(\mathrm{N}=0) \\
\mathrm{P}(\mathrm{N}=0)=\frac{1}{\sum_{\mathrm{N}=0}^{\mathrm{S}-1} \frac{(\lambda / \mu)^{\mathrm{N}}}{\mathrm{N} !}+\frac{(\lambda / \mu)^{\mathrm{S}}}{\mathrm{S} !} \cdot \frac{1}{1-\lambda / \mathrm{S} \mu}}
\end{gathered}
$$

Where $\quad \mathrm{P}(\mathrm{N} \geq \mathrm{S})$ : probability that all FLZs are occupied

$\mathrm{N}$ : number of commercial vehicles in the system

$\mathrm{S}:$ number of FLZs

$\lambda$ : commercial vehicle arrival rate (vehicles per hour)

$\mu:$ commercial vehicle service rate (vehicles per hour)

$\mathrm{P}(\mathrm{N}=0)=$ probability that all FLZs are empty

If a commercial driver waits when FLZs are fully occupied, the expected waiting time of the driver can be estimated as follows:

$$
\mathrm{W}_{\mathrm{q}}=\frac{\mathrm{P}_{\mathrm{o}}(\lambda / \mu)^{S}(\lambda / \mathrm{S} \mu)}{S !(1-\lambda / S \mu)^{2} \lambda}
$$

When a commercial driver waits until a FLZ is available, it is assumed that the driver waits inside the vehicle and since the vehicle is never left unattended, the "waiting" driver will not receive a parking fine.

When the driver double-parks a parking enforcement officer can issue a parking fine. However, an illegally parked vehicle does not always receive parking fines. This study models the expected probability of receiving a parking ticket or fine given that all FLZs are occupied $p_{t}$ as a function of service time $\left(\mathrm{t}_{\mathrm{s}}\right)$ and the parking enforcement cycle duration $\left(t_{e f}\right)$. The inverse of $\mu$ is the duration of the average parking zone utilization or $t_{s}$.

$$
\left.p_{t}=\operatorname{probability}(\text { ticket } \mid \mathrm{N} \geq \mathrm{S})\right)=\frac{\mathrm{t}_{\mathrm{s}}}{\mathrm{t}_{\mathrm{ef}}}
$$


An average parking utilization level $(\rho)$ is defined as the ratio of parking demand to parking supply $(\rho=\lambda / S \mu)$. Parking utilization and parking availability are inversely related, low parking utilization (low $\rho$ ) is associated with high parking availability or easiness to find empty loading zones.

\section{Routing Constraints}

Continuous approximations have been successfully used by many research efforts to model urban distribution systems (Langevin, A., Mbaraga, P., and Cambell, J. 1996; Daganzo C. 2005). This study utilizes a continuous approximation model successfully used in the past (Figliozzi M. 2008; Figliozzi M. 2010) to estimate the average route distance of commercial vehicles.

$$
\operatorname{VRP}(V)=k_{l} \frac{n-m}{n} \sqrt{n A}+2 \bar{r} m
$$

where $\quad \operatorname{VRP}(\mathrm{V})=$ average distance travelled for a fleet of $\mathrm{m}$ vehicles (miles)

$$
\begin{aligned}
& \mathrm{k}_{\mathrm{l}}=\text { local service area coefficients } \\
& \mathrm{n}=\text { number of customers } \\
& \mathrm{m}=\text { number of routes } \\
& \mathrm{A}=\text { the size of a service area }\left(\mathrm{km}^{2}\right) \\
& \overline{\mathrm{r}}=\text { average distance between customers and a depot }(\mathrm{km})
\end{aligned}
$$

The following parameters are utilized to formulate long-term service costs.

$\mathrm{L}^{\mathrm{i}}=$ Tour distance of vehicle type $\mathrm{i}$ (miles/tour)

$\mathrm{T}^{\mathrm{i}}=$ Tour duration of vehicle type i (hours)

$\mathrm{T}_{\max }=$ Maximum tour duration(hours)

$\mathrm{w}_{\mathrm{d}}=$ Average customer demand (lb./stop)

$\mathrm{t}_{\mathrm{s}}=$ Average service time (minute/stop)

$v_{\mathrm{a}}^{\mathrm{i}}=$ Average speed of vehicle i going from a depot to the service area (mph) 
$v_{b}^{i}=$ Average speed of vehicle i running inside the service area (mph)

$v_{c}^{i}=$ Average speed of vehicle i returning to the depot (mph)

$\mathrm{w}_{\mathrm{C}}^{\mathrm{i}}=$ Load capacity of vehicle type $\mathrm{i}(\mathrm{lbs})$

Route duration and vehicle capacity constraints can be expressed as follows:

$$
\begin{aligned}
& L^{i j}=\bar{r}+\frac{k_{l} \frac{n^{i j}-m^{i j}}{n^{i j}} \sqrt{n^{i j A}}}{m^{i j}}+\bar{r} \\
& T^{i j}=\frac{\bar{r}}{v_{a}^{i}}+\frac{k_{l} \frac{n^{i j}-m^{i j}}{n^{i j}} \sqrt{n A}}{m^{i j} v_{b}^{i}}+\frac{\bar{r}}{v_{c}^{i}}+n^{i j} t_{s}^{i}+\left(1-y_{i j}\right)\left(n^{i j} W_{q}(\rho)\right)
\end{aligned}
$$

$$
\begin{array}{ll}
\mathrm{m}^{\mathrm{ij}} \geq \mathrm{n}^{\mathrm{ij}} \cdot \mathrm{w}_{\mathrm{d}} / \mathrm{w}_{\mathrm{C}}^{\mathrm{i}} & \forall \mathrm{i} \in \mathrm{I}, \forall \mathrm{j} \in \mathrm{J} \\
\mathrm{T}_{\max } \geq \mathrm{T}^{\mathrm{ij}} & \forall \mathrm{i} \in \mathrm{I}, \forall \mathrm{j} \in \mathrm{J}
\end{array}
$$

The binary variable $y_{i j}$ indicates whether the vehicle double-parks $\left(y_{i j}=1\right)$ or waits for parking $\left(\mathrm{y}_{\mathrm{ij}}=0\right)$. These equations estimate the length of a delivery tour that starts from a depot, serves customers, and returns to the depot as well as tour duration. Average parking utilization levels $\rho$ and parking behaviour affect waiting time $\mathrm{W}_{\mathrm{q}}$ and can indirectly also affect fleet size when $\mathrm{T}^{\mathrm{ij}}$ increases over the maximum tour duration.

\section{Service Costs}

Long-term service cost includes vehicle depreciation cost, energy/fuel cost, vehicle maintenance cost, driver wage, driver annual costs, truck annual costs, and doubleparking fines. In the USA drivers' annual costs include driver health insurance, social security tax, Medicare tax, and pension/retirement; the truck annual costs include 
vehicle registration and insurance. The following indices are utilized to formulate longterm service costs.

$i \in\{$ set of vehicle types $\}=\mathrm{I}$

$j \in\{$ set of parking behaviors $\}=\mathrm{J} \quad j=1$ for double parking and $j=0$ for waiting or cruising for parking

$k \in\{$ set of years of the planning horizon $\}=\{1,2, \ldots, \mathrm{K}\}$

The following parameters are utilized to formulate long-term service costs.

$c_{p}^{i}=$ Unit purchase cost for vehicle type i (dollar/vehicle)

$c_{r}^{i}=$ Unit resale cost for vehicle type i $\left(\frac{\text { dollar }}{\text { vehicle }}\right)$ in year $\mathrm{K}$

$c_{\mathrm{e}}^{\mathrm{i}}=$ Unit energy cost for vehicle type i (dollar/gallon or dollar/kWh)

$\mathrm{r}_{\mathrm{e}}^{\mathrm{i}}=$ energy consumption rate of vehicle type $\mathrm{i}$ (gallon/mile or $\mathrm{kWh} / \mathrm{mile}$ )

$c_{\mathrm{m}}^{\mathrm{i}}=$ Unit maintenance cost for vehicle type $\mathrm{i}($ dollar $/ \mathrm{mile})$

$c_{1}^{i}=$ Hourly driver wage for vehicle type i (dollar/hour)

$c_{t}=$ parking fine (dollars)

$p_{t}^{i j}=$ Probability of receiving a parking for vehicle type i and behaviour type $\mathrm{j}$

$c_{\mathrm{a}}^{\mathrm{i}}=$ Unit annual cost for vehicle type i (dollar/vehicle)

$f_{d}=$ Discount factor $(\%)$

$\mathrm{f}_{\mathrm{e}}=$ Rate of inflation for diesel fuel $(\%)$

$\mathrm{d}=$ Days of service per year

$\mathrm{K}=$ Years in planning horizon

$\mathrm{m}^{\mathrm{ij}}=$ fleet size $\mathrm{m}^{\mathrm{i}, \mathrm{j}}$ (integer) of vehicles type $\mathrm{i}$ following parking behaviour $\mathrm{j}$

The sum of purchasing, resale, energy/fuel, maintenance, driver wages, parking tickets, and vehicle fixed annual costs can be expressed as follows: 


$$
\begin{aligned}
& C=\sum_{i} \sum_{j=1}^{J}\left[\left(\mathrm{c}_{\mathrm{p}}^{\mathrm{i}}-\left(1+\mathrm{f}_{\mathrm{d}}\right)^{-\mathrm{K}} \mathrm{c}_{\mathrm{r}}^{\mathrm{i}}\right) \mathrm{m}^{\mathrm{ij}}+\sum_{\mathrm{k}=1}^{\mathrm{K}}\left(1+\mathrm{f}_{\mathrm{d}}\right)^{-\mathrm{k}}\left(1+\mathrm{f}_{\mathrm{e}}\right)^{\mathrm{k}}\left(\mathrm{c}_{\mathrm{e}}^{\mathrm{i}} \mathrm{r}_{\mathrm{e}}^{\mathrm{i}} \mathrm{L}^{\mathrm{ij}} \mathrm{m}^{\mathrm{ij}} \mathrm{d}\right)+\right. \\
& \sum_{\mathrm{k}=1}^{\mathrm{K}}\left(1+\mathrm{f}_{\mathrm{d}}\right)^{-\mathrm{k}}\left(\mathrm{c}_{\mathrm{m}}^{\mathrm{i}} \mathrm{L}^{\mathrm{ij}} \mathrm{m}^{\mathrm{ij}} \mathrm{d}\right)+\sum_{\mathrm{k}=1}^{\mathrm{K}}\left(1+\mathrm{f}_{\mathrm{d}}\right)^{-\mathrm{k}}\left(\mathrm{c}_{1}^{\mathrm{i}} \mathrm{T}^{\mathrm{ij}} \mathrm{m}^{\mathrm{ij}} \mathrm{d}\right)+\sum_{\mathrm{k}=1}^{\mathrm{K}}\left(1+\mathrm{f}_{\mathrm{d}}\right)^{-\mathrm{k}}\left(\mathrm{c}_{\mathrm{t}} \mathrm{p}_{\mathrm{t}}^{\mathrm{ij}} \mathrm{m}^{\mathrm{ij}} \mathrm{d}\right)+ \\
& \left.\sum_{\mathrm{k}=1}^{\mathrm{K}}\left(1+\mathrm{f}_{\mathrm{d}}\right)^{-\mathrm{k}}\left(\mathrm{c}_{\mathrm{a}}^{\mathrm{i}} \mathrm{m}^{\mathrm{ij}}\right)\right] .
\end{aligned}
$$

\section{Optimization Problem}

The optimization problem minimizes long-term vehicle costs by selecting the best vehicle type $\mathrm{i}$ and parking behavior $\mathrm{j}$. The decision variable is the fleet size $\mathrm{m}^{\mathrm{i}, \mathrm{j}}$ (integer) of vehicles type $\mathrm{i}$ following parking behavior $\mathrm{j}$ and the number of customers $\mathrm{n}^{\mathrm{ij}}$ assigned to vehicle type $\mathrm{i}$ following parking behavior $\mathrm{j}$. The binary variable $\mathrm{y}_{\mathrm{ij}}$ is 1 when the vehicle double parks $(j=1)$ and zero otherwise $(j=0)$ when the driver waits until a parking space is available.

$C=$ Total cost over the planning horizon (dollars)

Minimize $C$

Subject to:

$$
\begin{array}{ll}
\mathrm{m}^{\mathrm{ij}} \geq \mathrm{n}^{\mathrm{ij}} \cdot \mathrm{w}_{\mathrm{d}} / \mathrm{w}_{\mathrm{C}}^{\mathrm{i}} \quad \forall \mathrm{i} \in \mathrm{I}, \forall \mathrm{j} \in \mathrm{J} \\
\mathrm{T}_{\max } \geq \mathrm{T}^{\mathrm{ij}} \quad \forall \mathrm{i} \in \mathrm{I}, \forall \mathrm{j} \in \mathrm{J} \\
\mathrm{p}_{\mathrm{t}}^{\mathrm{ij}}=\mathrm{y}_{\mathrm{ij}} \mathrm{p}_{\mathrm{t}} \leq 1 \quad \forall \mathrm{i} \in \mathrm{I}, \forall \mathrm{j} \in \mathrm{J} \\
\mathrm{n}^{\mathrm{ij}}, \mathrm{m}^{\mathrm{ij}} \geq 0 \quad \mathrm{n}^{\mathrm{ij}}, \mathrm{m}^{\mathrm{ij}} \in \text { Set of Integers } \quad \forall \mathrm{i} \in \mathrm{I}, \forall \mathrm{j} \in \mathrm{J} \\
\mathrm{m}^{\mathrm{ij}} \leq \mathrm{ny}^{\mathrm{ij}} \quad \forall \mathrm{i} \in \mathrm{I}, \mathrm{j}=1 \\
\mathrm{~m}^{\mathrm{ij}} \leq \mathrm{n}\left(1-\mathrm{y}^{\mathrm{ij}}\right) \quad \forall \mathrm{i} \in \mathrm{I}, \mathrm{j}=0 \\
\mathrm{n} \leq \sum_{i} \sum_{\mathrm{j}=1}^{J} \mathrm{n}^{\mathrm{ij}}
\end{array}
$$

Equation (1) is the objective function, minimization of total cost. Equation (2) is a weight/capacity constraint and equation (3) is a route duration constraint. Equation (4) estimates the probability of receiving a fine. Equation (5) is an integer non-negativity 
constraint. Equations (6) and (7) are logical constraints that link parking behaviour and fleet size. Equation (8) ensures that all customers are served.

The reader should note that the threshold for waiting or double parking is purely monetary. The model attempts to explain what factors may support a waiting or doubleparking strategy. It is assumed that loading zones are convenient for commercial vehicle drivers; another dimension of the problem is the situation when commercial drivers stop in the closest place (double-park) even when loading zones are free but not close enough to the final delivery location (a trade-off that is not analysed in this research).

\section{Case Study}

It is hypothesized that logistics constraints and route characteristics have an impact on parking costs, operations and behaviour. Two types of delivery services are analyzed: less-than-truckload (LTL) and courier deliveries. LTL deliveries are heavier and require more time per delivery than courier deliveries. LTL shipments can range between 600 and 1,200 lbs. (Morris and Kornhauser 2000) with service times ranging between 15 and 25 minutes per stop (Muñuzuri, Cortés, Guadix, and Onieva 2012). Courier services are lighter, ranging from less than 1 to $170 \mathrm{lbs}$. (Morris and Kornhauser 2000). Courier service time ranges from 1 to 5 minutes (Muñuzuri, Cortés, Guadix, and Onieva 2012). Four route types are studied in this is research but due to space constraints, only one vehicle type (a typical small delivery truck) is utilized in this research.

LTL and courier deliveries are classified into two groups: A and B; "A" types have heavier shipment sizes, longer service times, and longer tour durations than " $\mathrm{B}$ " types. The characteristics of customers LTL A, LTL B, Courier A and Courier B are summarised in Table 1 . The characteristics of the vehicle, a typical small delivery vehicle in the USA, are shown in Table 2. 
The model presented in Section 3 is utilized to minimize long-term service costs as a function of fleet size and changing demand and supply $(\rho=\lambda / S \mu)$ ratios but conditional on utilizing one strategy (waiting or double-parking). Scenarios LTL A and LTL B are weight-constrained whereas Courier A and Courier B scenarios are timeconstrained.

\section{Impacts of Parking Availability on Costs}

Long-term costs are estimated for each scenario as a function of parking availability. The results show that the impacts of parking availability are different for the double parking and waiting strategies. Figure 1 shows the expected probability of no parking and the expected waiting time as a function of parking utilization levels $\rho$. The rate of increase of the probability of no parking is steady and comparable across different service types. However, expected waiting time varies significantly across delivery types. For the sake of simplicity, only LTL A and Courier B graphs are shown in Figure 1; the other two scenarios (LTL B and Courier A) fall in between LTL A and Courier B scenarios and are not included for the sake of brevity.

For LTL A routes, with longer service times, the increase of expected wait times as a function of $\rho$ starts to show high values - more than 5 minutes per customer - for parking utilization values $\rho>0.60$. On the other hand, for Courier B routes, the increase of expected wait time as a function of parking utilization values starts to show high values - more than 5 minutes per customer - for values $\rho>0.90$. In the latter scenario, the increase is very sharp when $\rho>0.90$.

Costs per customer (per stop) are shown in Figure 2. For the sake of simplicity, only the LTL A and Courier B curves are shown. In terms of absolute costs, as expected, courier deliveries are several times more economical than LTL deliveries. 
This is expected because it is more difficult to deliver heavier loads that have longer service times; more routes, drivers, and vehicles are necessary to accommodate fewer LTL customers per route. Courier routes are several times more efficient in terms of utilization of resources such as vehicles and drivers.

The comparison of the costs of double parking and waiting strategies are less straightforward. For LTL A deliveries, it is better to "wait" than to double park until $\rho$ $\cong 0.90$; for Courier B deliveries, it is better to "wait" than to double park until $\rho \cong 0.70$. The results indicate that for Courier B double parking is a nearly optimal strategy for any $\rho$ value, since the difference between the cost of double parking and waiting can be barely perceived in the interval $0<\rho<0.70$. In other words, Couriers are nearly indifferent between double parking and waiting in the interval $0<\rho<0.70$. On the other hand, for LTL A services the difference between the cost of double parking and waiting is noticeable in the range $0.40<\rho<0.90$.

These results indicate that the impact of parking availability on LTL and Courier operations and behaviour are likely different. In areas with a reduced number of loading zones and high parking demand it is expected that Courier vehicles will show a tendency to double-park more than LTL vehicles. For LTL vehicles, waiting is a more attractive option. LTL vehicles have longer service times and hence the probability of parking fines are high when the vehicles are not legally parked. The parking utilization must be high $(\rho>0.90)$ and waiting times must be very long to outweigh the expected parking fine costs.

\section{Per-Stop Elasticity Analysis}

Previous results are useful to highlight general trends regarding occupancy, waiting times, cost per customer, route type, and parking demand/supply ratios. Elasticity values 
are calculated in this section to get an estimate of the relative importance of service, routing, and parking variables on long-term cost per stop or customer.

The elasticity analysis was conducted at break-even values $(b)$ of $\rho$ where the service cost of the double-parking behaviour equals the service cost of the waiting behaviour. The breakeven points were chosen because at these points small changes may result in behaviour reversals, e.g. from waiting to double parking or vice versa. The elasticities were obtained using numerical approximations of this function:

$$
E(C / n, x)=\frac{\frac{\partial(C(x, b) / n)}{\partial x}}{\frac{C(x, b) / n}{x}}
$$

where:

$E(C / n, x)=$ variable $x$ long-term service cost per stop elasticity

$C(x, b) / n=$ per customer or stop long-term service cost

$b=$ breakeven point

Table 3 provides the elasticity values for the LTL B scenario. To facilitate a comparison, elasticity values are sorted from highest to lowest value when $j=1$ (double-park). A positive sign must be interpreted as an increase in per stop cost, for example, if the value of the parking fine increases $1 \%$ the per stop cost is going to increase $0.6 \%$ if the driver decides to double park and $0.0 \%$ if the driver decides to wait for an available parking space.

As expected, when $\rho$ increases there is a major increase in service costs but at the breakeven point the increase is three times higher if the driver decides to wait instead of double park. The ratio between $E(C / n, \rho)$ and $E\left(C / n, \mathrm{c}_{\mathrm{t}}\right)$ indicates that at 
the breakeven point fines must increase more than $2.3(1.37 / 0.6 \approx 2.3)$ times faster than the demand/supply ratio $(\rho)$ to make double parking less appealing.

Service time has a high elasticity in the double parking scenario, almost four times higher than in the wait scenario. This is may be explained by the fact that a service time increase also increases the probability of receiving a parking fine while double parking. Hence, in the double parking scenario a longer service time creates an indirect cost increase related to parking fines and a direct cost increase related to longer route durations. The reverse, a reduction of service time leads to a decrease in service costs but because the decrease is much faster for companies that double park, a decrease in service time moves the breakeven point between double-parking and waiting to the left or a smaller demand/supply ratio $(\rho)$. Driver hourly wage is the other variable that has a high impact on costs, especially in the waiting time scenario.

Variables related to route length such as service area size and distance depotservice area have a relatively small elasticity; the same can be said about the travel speeds. Vehicle purchase cost elasticity is more important in the wait scenario but it is five times smaller than the elasticity value for driver wages, $E\left(C / n, c_{1}\right)=0.65$ and $E\left(C / n, \mathrm{c}_{\mathrm{p}}\right)=0.13$. Other costs such as energy or the value of money (discount rate) have low elasticity values.

Table 4 provides the elasticity values for the Courier-A scenario. Overall, the same trends are maintained. However, a major jump is observed in the elasticity value for $\rho$ if the vehicle waits. At the breakeven point, for any given increase in $\rho$ the resulting increase in service costs per stop is 5.2 times higher if the driver decides to wait instead of double parking.

The ratio between $E(C / n, \rho)$ and $E\left(C / n, \mathrm{c}_{\mathrm{t}}\right)$ indicates that at the breakeven point fines must increase more than $2.3(1.17 / 0.5 \approx 2.34)$ times faster than the 
demand/supply ratio $(\rho)$ to make double parking less appealing. The value of this ratio is similar to the value found in the LTL scenario.

\section{Discussion}

Two key policy insights can be derived from the results: (a) double parking is unlikely to disappear from urban areas unless more dedicated freight and service parking spaces are available at peak times and (b) increasing parking fines and parking enforcement can discourage double parking but it will not eradicate the problem for sufficiently high values of demand/supply ratios $(\rho)$. In the long-term, urban policy may be more productive when the focus is on requiring enough on-street and off-street parking spaces for freight and service vehicles. These conclusions roughly agree with previous studies (Wenneman, A., Habib, K. and Roorda, M. 2015; Chen, Q. and Conway, A. 2016).

For managers at delivery or service companies the options seem limited as well. Large package delivery companies such as FedEx or UPS understand that parking fine costs are just another element of the cost of doing business in congested urban areas. Pricing policies can reflect this additional cost (as in the cited case for UPS in Manhattan) which means that parking costs are eventually transferred to consumers in the forms of extra costs such as service or delivery fees. Alternatively, companies can try to lower service times or delivery costs. Some costs are not transferred to direct consumers of freight or commercial services, for example double parking severely restricts needed roadway capacity during peak hours which causes congestion and emissions; congestion impacts are mainly a function of service times or double-parking duration (Lopez et al., 2016).

For companies that double park when parking is not available the largest cost reduction is obtained when service times are reduced. For example, delivering packages 
to a package dropbox at the ground level entrance of a building can save valuable minutes otherwise spent at the elevator or carrying a hand truck through long hallways. For companies that usually wait or cruise until parking is available the largest cost reduction is obtained when driver wages are reduced. Significant driver wage cuts aan option in a competitive labour market and long-term cost reductions are usually achieved by decreasing service times or increasing driver productivity.

Managers have an incentive to increase productivity by reducing service times, but a reduction in service times makes (ceteris paribus) double-parking a rational response for a wider range demand/supply ratios $(\rho)$. On the other hand, a reduction of driver wages makes (ceteris paribus) waiting a rational response for a wider range demand/supply ratios $(\rho)$. Finally, it is worth noting that increasing passenger parking fees and assigning just a small percentage of parking to commercial vehicles produces a significant social surplus (Amer \& Chow, 2016). However, in practice it also important to monitor that commercial vehicle zones are not taken by passenger vehicles; increased monitoring may increase (government) costs if parking fines do not cover the cost of enforcement.

\section{Conclusions}

This study addressed the following research questions: how does parking availability affect distribution companies' parking behaviour? and (ii) what are the key variables that affect parking costs? A model where long-term service costs and fleet size are affected by changes in parking demand/supply ratios was formulated. The model also accounts for different parking strategies such as double-park when necessary or wait/cruise until parking is available. 
Results show that as parking availability decreases, costs increase more rapidly for LTL services than for Courier services. The difference in cost changes is related to customer service times and route structures. It is also observed that LTL services are more likely to cruise or wait until parking becomes available than Courier services. LTL vehicles have longer service times and hence the probability of parking fines are higher if the vehicles are not legally parked. The parking utilization must be high and waiting times long to outweigh expected parking fine costs for LTL deliveries.

The results also indicate that double parking can be a company's rational response, especially for Courier type services, in urban environments with high parking demand/supply ratios. Parking policy options to tackle commercial vehicle double parking are limited and perhaps bound to fail in the long-term unless development codes require enough on-street and off-street parking spaces for freight and service vehicles. A novel result is that increases in logistics or service productivity achieved through a reduction in service times makes (ceteris paribus) double-parking a rational response for a wider range of demand/supply ratios $(\rho)$. This demonstrates the intricacy of the commercial vehicle parking problem, changes at the route or customer level (that are hard to observe for a public transportation agency) may result in undesirable (but rational from a private company perspective) changes in commercial vehicle parking behaviour. 


\section{References}

Amer, A., \& Chow, J. Y. (2016). A downtown on-street parking model with urban truck delivery behavior. Transportation Research Part A: Policy and Practice.

Aiura, N. and Taniguchi, E. (2006) Planning On-Street Loading-Unloading Spaces Considering the Behaviour of Pickup-Delivery Vehicles and Parking Enforcement. Recent Advances in City Logistics, the 4th International Conference on City Logistics, pp. 107-119. Langkawi (Malaysia): Elsevier.

Berezin, L. (2014) Double Parking Ticket Blitz will cost you a \$115 Parking Fine, in: the New York Parking Ticket: http://newyorkparkingticket.com/double-parking-ticketblitz-will-cost-115-parking-fine/ (accessed 30.08.15)

Chen, Q., \& Conway, A. (2016). Commercial Vehicle Parking Availability and Behavior for Residential Delivery in New York City. In Transportation Research Board 95th Annual Meeting (No. 16-4597).

City of New York. (2013) Trucks \& Commercial Vehicles.

http://www.nyc.gov/html/dot/html/motorist/trucks.shtml (accessed 22.10.16)

Daganzo, C. F. (2005) Logistics Systems Analysis. Springer.

Durand, B., \& Gonzalez-Feliu, J. (2012, January). Impacts of proximity deliveries on egrocery trips. In Supply Chain Forum: An International Journal (Vol. 13, No. 1, pp. 10-19). Taylor \& Francis.

Figliozzi, M. A. (2007). Analysis of the efficiency of urban commercial vehicle tours: Data collection, methodology, and policy implications. Transportation Research Part B: Methodological, 41(9), 1014-1032.

Figliozzi, M. A. (2008) Planning Approximations to the Average Length of Vehicle Routing Problems with Varying Customer Demands and Routing Constraints, in: the Transportation Research Record: Journal of the Transportation Research Board, 2089, pp. 1-8.

Figliozzi, M. A. (2010) The impacts of congestion on commercial vehicle tour characteristics and costs, in: the Transportation Research Part E: Logistics and Transportation Review, 46, pp. 496-506.

Figliozzi, M \& Tipagornwong, C. (2016, June). The Impact of Last Mile Parking Availability on Commercial Vehicle Costs in Congested Urban Areas, In Information Systems Logistics and Supply Chain: ILS Conference 2016: Building a Resilient Future.

Fischer, M. J., \& Han, M. (2001) NCHRP Synthesis 298: Truck Trip Generation Data: A Synthesis of Highway Practice. Washington D.C.: Transportation Research Board.

Gordon, R. (2007) Parking tickets by the truckload / 18 S.F. businesses rack up thousands of citations, pay city on monthly plan, in: SF GATE:

http://www.sfgate.com/news/article/Parking-tickets-by-the-truckload-18-S-F2615428.php (accessed 30.08.2016)

Halsey, A. (2013) In D.C., parking tickets are a cost of doing business, in: the Washington Post: https://www.washingtonpost.com/local/trafficandcommuting/indc-parking-tickets-are-a-cost-of-doing-business/2013/06/01/6c693a56-b357-11e29a98-4be1688d7d84 story.html (accessed 30.08.2016) 
Hawkins, A. J. (2013) Parking tickets: All in the cost of doing business, in: Crain's New York Business

http://www.crainsnewyork.com/article/20130526/ECONOMY/305269980/parkingtickets-all-in-the-cost-of-doing-business (accessed 30.08.2016)

Jaller, M., Holguín-Veras, J., \& Hodge, S. (2013). Parking in the city: Challenges for freight traffic. Transportation Research Record: Journal of the Transportation Research Board, (2379), 46-56.

NBC News. (2006) Delivery firms' big ticket item: Parking fines, in: NBC News.com: http://www.nbcnews.com/id/14602712/ns/business-us business/t/delivery-firmsbig-ticket-item-parking-fines/\#.Vg8M7 1VhBd (accessed 30.08.16)

Langevin, A., Mbaraga, P., and Cambell, J. F. (1996) Continuous approximation models in freight distribution: An overview, in: the Transportation Research Part B: Methodological, 30, pp.163-188.

Lopez, C., Gonzalez-Feliu, J., Chiabaut, N., \& Leclercq, L. (2016, June). Assessing the impacts of goods deliveries' double line parking on the overall traffic under realistic conditions. In Information Systems Logistics and Supply Chain: ILS Conference 2016: Building a Resilient Future.

Marcucci, E., Gatta, V., \& Scaccia, L. (2015). Urban freight, parking and pricing policies: An evaluation from a transport providers' perspective. Transportation Research Part A: Policy and Practice, 74, 239-249.

Millard-Ball, A., Weinberger, R. R., and Hampshire, R. C. (2014) Is the curb 80\% full or $20 \%$ empty? Assessing the impacts of San Francisco's parking pricing experiment, in: the Transportation Research Part A, 63, pp. 76-92.

Morris, A. G., and Kornhauser, A. L. (2000) Relationship of Freight Facilities in Central Business District Office Buildings to Truck Traffic, in the Transportation Research Record: Journal of the Transportation Research Board, 1707, pp. 56-63.

Morris, A. G., Kornhauser, A. L., \& Kay, M. J. (1999) Getting the Goods Delivered in Dense Urban Areas: A Snapshot of Last Link of the Supply Chain, in: the Transportation Research Record: Journal of the Transportation Research Board, 1653, pp. 34-41.

Muñuzuri, J., Cortés, P., Guadix, J., and Onieva, L. (2012) City logistics in Spain: Why it might never work, in: Cities, 29, 133-141.

Pluvinet, P., Gonzalez-Feliu, J., Faivre d'Arcier, B., Gardrat, M., Basck, P., Ambrosini, C., \& Routhier, J.L. (2012). Methodology, evaluation, simulation and assessment for the analysis of the deployment of DSB and EEIC systems of the FREILOT project. Contribution of LET. Research report, Laboratoire d'Economie des Transports, Lyon.

Wenneman, A., Habib, K. \& Roorda, M. (2015). Disaggregate analysis of relationships between commercial vehicle parking citations, parking supply, and parking demand. Transportation Research Record: Journal of the Transportation Research Board, (2478), 28-34.

United Parcel Service of America. (2015) 2015 UPS Rate and Service Guide: Retail Rates. http://www.ups.com/media/en/retail_rates.pdf (accessed 13.07.15) 


\section{ACKNOWLEDEGEMENTS}

Financial support for this research was provided by the Freight Mobility Research Institute (Transportation Center) and the Transportation Technology and People lab at Portland State University. Any omissions or mistakes are the sole responsibility of the authors. 
Table 1. Route and Service Characteristics

\begin{tabular}{|l|l|l|l|l|}
\hline \multirow{2}{*}{ Parameter } & \multicolumn{4}{c|}{ Scenario } \\
\cline { 2 - 5 } & LTL A & LTL B & Courier A & Courier B \\
\hline Number of daily stops & 400 & 400 & 400 & 400 \\
\hline Service area size (sq. mile.) & 8.5 & 8.5 & 8.5 & 8.5 \\
\hline $\begin{array}{l}\text { Distance between a depot and a service } \\
\text { area (miles) }\end{array}$ & 4.5 & 4.5 & 4.5 & 4.5 \\
\hline Customer demand (lb./stop) & 450 & 80 & 10 & 10 \\
\hline Service time (minutes) & 20 & 6 & 3 & 3 \\
\hline Time window (hours) & 8 & 6 & 4 & 2 \\
\hline Planning horizon (years) & 5 & 5 & 5 & 5 \\
\hline $\begin{array}{l}\text { Average speed (mph) } \\
\text { - Inside service area } \\
\text { - Outside service area }\end{array}$ & 10 & 10 & 10 & 10 \\
\hline Delivery days per year & 30 & 30 & 30 & 30 \\
\hline Discount factor & 260 & 260 & 260 & 260 \\
\hline Fuel/energy inflation & $6.5 \%$ & $6.5 \%$ & $6.5 \%$ & $6.5 \%$ \\
\hline
\end{tabular}

Table 2. Characteristics of a Single Unit Truck

\begin{tabular}{|l|c|}
\hline Parameter & Truck \\
\hline Make & Isuzu N-series \\
\hline Fuel tank / battery size & 25 gallon \\
\hline Fuel / electricity consumption rate & $10 \mathrm{mpg}$ \\
\hline Gross vehicle weight & $12,000 \mathrm{lbs}$. \\
\hline Tare & $5,672 \mathrm{lbs}$. \\
\hline Payload & $6,328 \mathrm{lbs}$. \\
\hline Lifetime & 12 years \\
\hline Purchase cost & $\$ 50,000$ \\
\hline Maintenance cost & $\$ 0.20 /$ mile \\
\hline Vehicle insurance & $\$ 2,336 /$ year \\
\hline Vehicle registration & $\$ 391 /$ year \\
\hline Diesel / electricity cost & $\$ 2.689 /$ gal \\
\hline Driver wage & $\$ 16.28 /$ hour \\
\hline Driver health insurance & $\$ 7,000 /$ year \\
\hline Driver Social Security/Medicare taxes & $7.65 \%$ of driver compensation \\
\hline Driver pension/retirement & $25 \%$ of driver compensation \\
\hline
\end{tabular}


Table 3. Elasticity Values for the LTL-B Scenario

\begin{tabular}{|l|r|r|}
\hline \multicolumn{1}{|c|}{ Variable } & $\begin{array}{c}j=1 \\
\text { (double-park) }\end{array}$ & $\begin{array}{l}j=0 \\
\text { (wait) }\end{array}$ \\
\hline Demand/supply ratio $(\rho)$ & 1.37 & 3.85 \\
\hline Service time, $\mathrm{t}_{\mathrm{s}}$ & 0.80 & 0.21 \\
\hline Parking fine, $\mathrm{c}_{\mathrm{t}}$ & 0.60 & 0.00 \\
\hline Driver wage, $\mathrm{c}_{\mathrm{l}}$ & 0.25 & 0.65 \\
\hline Purchase cost, $\mathrm{c}_{\mathrm{p}}$ & 0.06 & 0.13 \\
\hline Discount factor, $\mathrm{f}_{\mathrm{d}}$ & 0.02 & 0.04 \\
\hline Service Area $(\mathrm{SA}) \mathrm{Size}, A$ & 0.02 & 0.03 \\
\hline Distance depot to SA, $r$ & 0.02 & 0.05 \\
\hline Energy cost, $\mathrm{c}_{\mathrm{e}}$ & 0.01 & 0.02 \\
\hline Speed outside SA, $v_{\mathrm{a}}$ & -0.02 & -0.03 \\
\hline Speed inside $\mathrm{SA}, v_{\mathrm{b}}$ & -0.04 & -0.04 \\
\hline
\end{tabular}

Table 4. Elasticity Values for the Courier-A Scenario

\begin{tabular}{|l|r|r|}
\hline \multicolumn{1}{|c|}{ Variable } & $\begin{array}{c}j=1 \\
\text { (double-park) }\end{array}$ & $\begin{array}{l}j=0 \\
\text { (wait) }\end{array}$ \\
\hline Demand/supply ratio $(\rho)$ & 1.17 & 6.13 \\
\hline Service time, $\mathrm{t}_{\mathrm{s}}$ & 0.68 & 0.18 \\
\hline Parking fine, $\mathrm{c}_{\mathrm{t}}$ & 0.50 & 0.00 \\
\hline Driver wage, $\mathrm{c}_{\mathrm{l}}$ & 0.27 & 0.57 \\
\hline Purchase cost, $\mathrm{c}_{\mathrm{p}}$ & 0.08 & 0.16 \\
\hline Discount factor, $\mathrm{f}_{\mathrm{d}}$ & 0.04 & 0.05 \\
\hline Service Area $(\mathrm{SA})$ Size, $A$ & 0.03 & 0.03 \\
\hline Distance depot to SA, $r$ & 0.03 & 0.07 \\
\hline Energy cost, $\mathrm{c}_{\mathrm{e}}$ & 0.02 & 0.03 \\
\hline Speed outside SA, $v_{\mathrm{a}}$ & -0.02 & -0.03 \\
\hline Speed inside SA, $v_{\mathrm{b}}$ & -0.07 & -0.07 \\
\hline
\end{tabular}


Figure 1. Occupancy and Average Waiting Time vs. parking utilization $(\rho)$

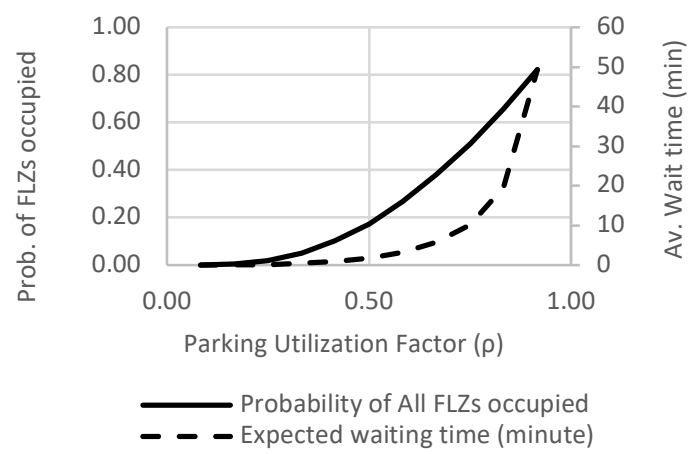

LTL A (service time $=20 \mathrm{~min})$

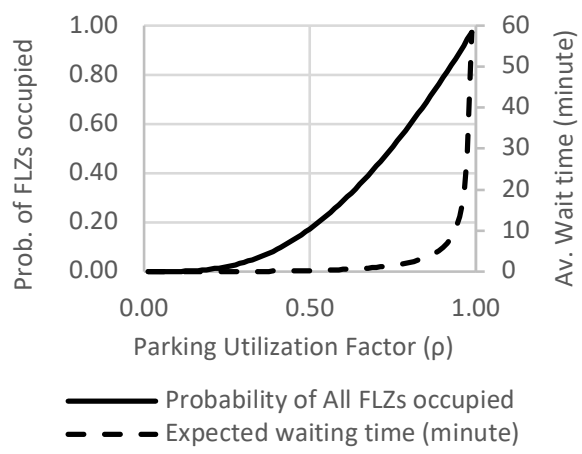

Courier B (service time $=3 \mathrm{~min}$ )

Figure 2. Long-term per-stop costs vs. parking utilization $(\rho)$

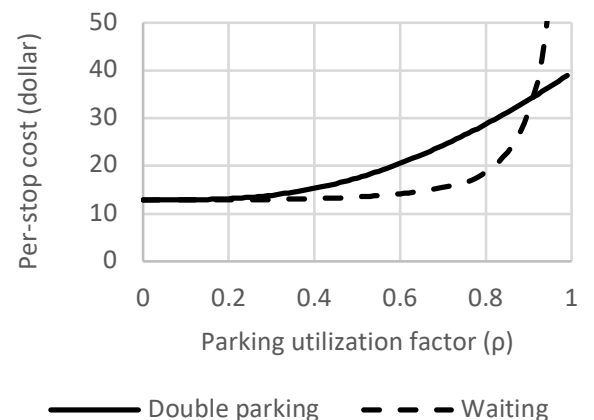

LTL A

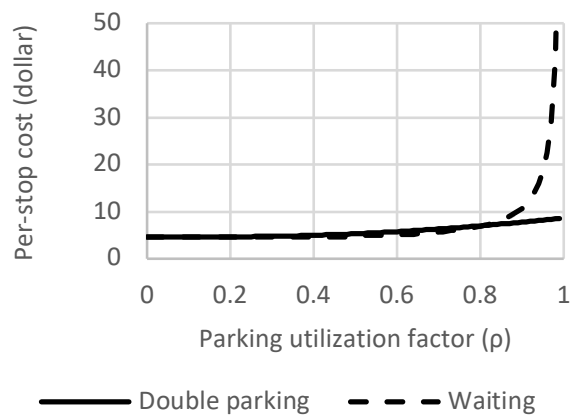

Courier B 